\section{JURNAL EKONOMI EFEKTIF}

ISSN : $2622-8882$, E-ISSN : 2622-9935

Jurnal Ekonomi Efektif, Vol. 4, No. 1, Oktober 2021 @Prodi Manajemen Fakultas Ekonomi Universitas Pamulang

\title{
PENGARUH FASILITAS DAN KUALITAS PELAYANAN TERHADAP KEPUASAN KONSUMEN MENGGUNAKAN JASA VEGA HOTEL KOTA SORONG
}

\author{
Aprilia Kabalmay ${ }^{1}$, Ramli Lewenussa ${ }^{2}$, Rais Dera Pua Rawi ${ }^{3 *}$ \\ Universitas Muhammadiyah, Sorong, Papua Barat, Indonesia \\ raisderaprawi@um-sorong.ac.id
}

Manuskrip: September -2021; Ditinjau: Oktober: -2021; Diterima: Oktober-2021; Online: Oktober-2021; Diterbitkan: Oktober-2021

\begin{abstract}
ABSTRAK
Penelitian ini bertujuan untuk mengetahui apakah Fasilitas dan Kepuasan Konsumen yang mempengaruhi kepuasan Konsumen menggunakan jasa Vega Hotel Kota Sorong. Penelitian ini menggunakan metode penelitian kuantitatif Deskriptif dan Korelasi. Populasi berjumlah 38 orang dengan sampel berjumlah 35 orang diturunkan dari rumus slovin. Metode analisis data menggunakan analisis regresi linear bergandadan pengujian hipotesis (uji-t dan uji koefisien determinasi). Data primer penelitian ini diperoleh dengan menyebarkan kuesioner kepada resonden dan di kumpulkan kembali, dengan menggunakan pengukurannya yaitu skala likert. Hasil dari analisis regresi linear berganda yang telah dilakukan menggunakan program aplikasi SPSS versi 20 for windows di peroleh hasil $\mathrm{Y}=-6.918+$ $0,507 \mathrm{X} 1+0,542 \mathrm{X} 2$ Hasil uji t melalui pengujian hipotesis dan kemudian dibandingkan dengan $\mathrm{t}$ tabel yaitu $\mathrm{n}=$ jumlah sampel 35 dengan $\alpha=0,05$ maka didapat tabel sebesar 1.68957 .
\end{abstract}

Kata Kunci: Fasilitas, Kualitas Pelayanan, dan Kepuasan Konsumen

\begin{abstract}
This study aims to determine whether the facilities and customer satisfaction that affect customer satisfaction using the services of Vega Hotel Kota Sorong. This research uses descriptive quantitative research methods and correlation. The population in this study were 38 users with a sample of 35 people derived from the Slovin formula. Methods of data analysis using multiple linear regression analysis and hypothesis testing (t-test and coefficient of determination). Primary data of this study were obtained by distributing questionnaires to respondents and collected again, using the measurement, namely the Likert scale. The results of the multiplelinear regression analysis that have been carried out using the SPSS version 20 for windows application program have the results $Y=-6.918+0.507 X 1+0.542 X 2$ The results of the t test are through hypothesis testing and then compared with t table, namely $n$ $=$ number of samples 35 with $\alpha=0.05$, the table is 1.68957 .
\end{abstract}

Keyword: Facility, Service Quality, \& Customer Satisfaction 


\section{PENDAHULUAN}

Bagi Indonesia khususnya Papua Barat yang memiliki potensi pariwisata yang potensial, kegiatan kepariwisataan diharapkan mampu menjadi salah satu kekuatan pembangunan yang dapat diandalkan, karena mampu menyumbangdevisa yang berasal dari belanja wisatawan mancanegara. Selain itu pendapatan sektorpariwisata juga berasal dari pengeluaranwisatawan nusantara.

Pariwisata mempunyai peran penting dan strategis dalam pembangunan nasional. UndangUndang RI No. 10 Tahun 2009 tentang Kepariwisataan menyatakan bahwa kepariwisataan bertujuan antara lain untuk meningkatkan pertumbuhan ekonomi, meningkatkan kesejahteraan rakyat, menghapuskan kemiskinan, mengatasi pengangguran, memajukan kebudayaan, dan mengangkat citra bangsa.

Hotel merupakan jasa akomodasi yang didalamnya terdapat unsur pelayanan, kenyamanan serta fasilitas penginapan yang dibutuhkan bagi mereka yang menghendaki sarana penginapan untuk kepentingankeluarga maupun liburan.

Kualitas pelayanan merupakan suatu bentuk penilaian konsumen terhadap tingkat pelayanan yang diterima (perceived service) dan tingkat layanan yang diharapkan (expected service). Semakin meningkatnya jumlah wisatawan di Indonesia khususnya Papua Barat maka perlu diimbangi dengan peningkatan penyediaan kamar/akomodasi pada hotel. Sehingga tidak menimbulkan kesenjangan antara permintaan dan penawaran atas kamar/ tersebut. Akomodasi/kamar merupakan faktor yang sangat penting karena merupakan "rumah sementara" bagi wisatawan yang mengharapkan kenyamanan, pelayanan yang baik, kebersihan dan lain-lain.

Kualitas pelayanan akan dihasilkanoleh operasional yang dilakukan perusahaan dan keberhasilan proses operasi perusahaan ditentukan oleh banyak faktor antara lain pegawai, teknologi system, dan keterlibatan konsumen memberikan kontribusi terhadapkualitas pelayanan yang diciptakan.

Persaingan yang ketat juga menyebabkan para manjer berlomba-lomba untuk menawarkan value yang lebih sebagai daya tarik konsumen terhadap hotel, mereka mulai menambahkan dari segi makanan, minuman, fasilitas lain yang menambah daya tarik konsumen. Selain itu juga menambahkan ornament atau fasilitas kamar yang lebih aman dan nyaman. Konsumen tentunya akan memilih penginapan atau hotel sesuai dengan kriteria yang sesuai dengan keinginan mereka. Berbagai konsumen tentunya memiliki minat yang berbeda-beda akan hal tersebut. Konsumen dari kalangan menengah biasanya lebih menekankan pada harga yang terjangkau dan kamar yangmemadai.

Sedangkan konsumen golongan menegah keatas mereka lebih cenderung untuk memilih hotel dengan fasilitas full music, swalayan, cafe, room servis serta fasilitas lain yang mengutamakan kualitas tanpa memperhatikan harga. Maka dari situlah pihak manajemen hotel harus cerdas dalam mengatur mengenai kriteria atau keinginan konsumen.Perkembangan industri perhotelan, salah satunya dapat dilihat melalui indikator tingkat penghunian kamar hotel dan rata-rata lamanya tamu menginap.

Tingkat Penghunian Kamar Hotel (TPK) adalah jumlah kamar yang telah disewakan/dihuni dibandingkan dengan jumlah kamar yang tersedia di hotel tersebut dan Rata-rata Lamanya Tamu Menginapadalah banyaknya malam tempat tidur yang dipakai dibagi dengan banyaknya tamu yang datang menginap. Rata - rata lamanya tamu menginap ini dapat dibedakan antara tamuasing dan tamu dalam negeri.

Di setiap daerah tentunya mempunyai tingkat penghunian kamar (TPK) berbintang di kota Sorong sendiri pada Februari 2019 mencapai 52,75 persen, hal ini menunjukkan bahwa kamar yang terpakai sebanyak 52,75 dari total kamar hotel berbintang yang tersedia di kota sorong. Rata - rata lama menginap tamu dan Indonesia pada hotel berbintang di kota sorong 
mencapai 3,75 (3-4 hari) selama februari 2019. Secara kesluruhan, rata - rata lama menginap tamu asing februari 2019 sebesar 2,94 (2-3) hari), sedangkan tamu domestic sebesar 1,64 (1-2 hari).

Maka dari itu berdasarkan latar belakang diatas peneliti tertarik untukmelihat sejauh mana jaminan pihak Hotel Vega Kota Sorong dalam memberikan keyakinan terhadap para pelanggannya, oleh sebab itu peneliti tertarik mengangkat judul: "Pengaruh Fasilitas Dan Kualitas Pelayanan Terhadap Kepuasan Konsumen Menggunakan Jasa Vega Hotel Kota Sorong”.

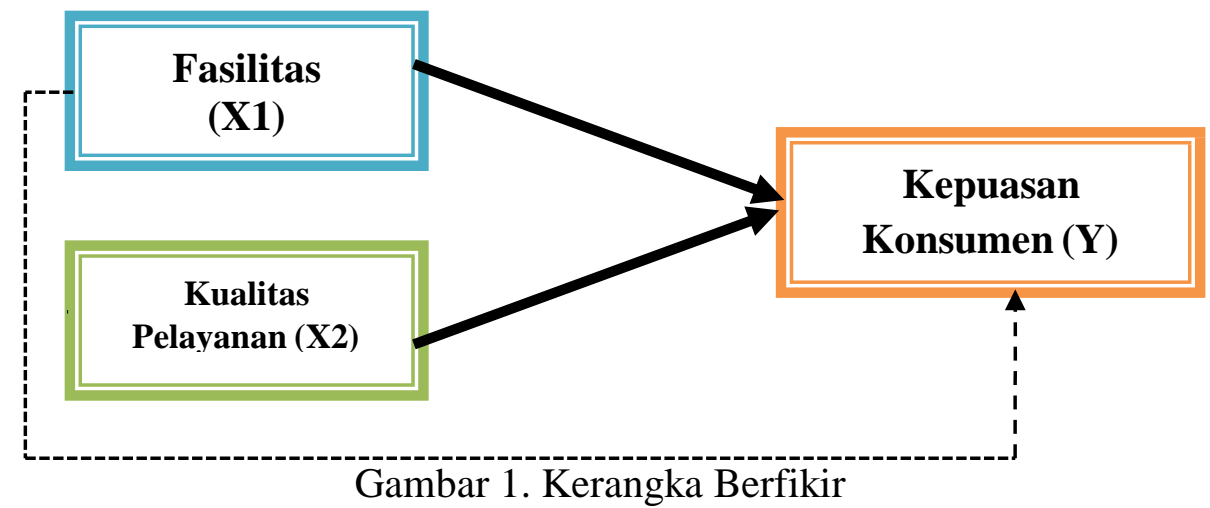

\section{TINJAUAN PUSTAKA}

\section{Fasilitas}

Fasilitas adalah sarana untuk melancarkan dan memudahkan pelaksanaan fungsi. Fasilitas merupakan komponen individual dari penawaran yang mudah ditumbuhkan atau dikurangi tanpa mengubahkualitas dan model jasa. fasilitas juga adalah alat untuk membedakan progam lembaga yang satu dengan pesaing yang lainya.

\section{Kualitas Pelayanan}

Menurut Tjiptono Kualitas Pelayananadalah upaya pemenuhan kebutuhan yang dibarengi dengan keinginan konsumen serta ketepatan cara penyampaiannya agar dapat memnuhi harapan dan kepuasan pelanggan tersebut. Pelayanan pada hakekatnya adalah serangkaian kegiatan atau merupakan proses yang berlangsung secara rutin dan berkesinambungan, meliputi seluruhkehidupan orang dalam masyarakat.

\section{Kepuasan Konsumen}

Menurut teori yang di introduksi oleh Anderson dalam Tjiptono. Kepuasan konsumen adalah penyimpangan (deviasi) dari ekspeksinya dalam batas tertentu (zone of acceptance). Apabila produk atau jasa yang di beli dan di konsumsi tidak terlalu berbeda dengan apa yang di harapkan pelanggan, maka kinerja produk atau jasa bersangkutan akan dievaluasi secara positif (dinilai memuaskan). Akan tetapi, jika kinerja produk atau jasa melampaui zone penerimaan konsumen, maka perbedaan yang ada akan dikontrantaskan sedemikian rupa sehingga akan tampak lebih besar dari sesungguhnhya.

\section{METODE PENELITIAN}

Metode dalam penelitian ini menggunakan metode korelasi dan deskriptif. Metodekorelasi adalah untuk mengetahui ada atau tidak adanya hubungan antara dua atau beberapa variabel sedangkan metode deskriptif adalah untuk menjelaskan, menggambarkan atau memaparkan variabel - variabel yang diteliti. 
Penelitian ini dilaksanakan mulai bulan Juni-Agustus 2020, bertempat di Vega Hotel Jl.Frans Kaisepo no 28, Km 7 Kota Sorong. Populasi dalam penelitian ini adalah para konsumen yang singgah di Vega Hotel Sorong. Sedangkan Sampel dalam penelitian ini diambil berdasarkan populasi, yaitu berjumlah 35 responden. Sumber data yang digunakan adalah data primer yang berupa hasil penyebaran kuesioner yang harus dioleh menggunakan aplikasi SPSS 20.

Dalam rangka memperoleh data-data yang peneliti perlukan, maka peneliti menggunakan beberapa metode pengumpulan data yaitu dokumentasi dan studi literatur. Untuk mengukur keeratan hubungan variabel dan memecahkan masalah digunakan metode analisis regresi linear berganda.

\section{HASIL PENELITIAN}

\section{Analisis Regresi Linier Berganda}

Regresi linier berganda bertujuan untuk menguji hubungan pengaruh antara satu variabel dependen terhadap lebih dari satu variabel independen.

Tabel 1. Hasil Regresi Linier Berganda

\begin{tabular}{|l|l|c|c|c|}
\hline \multicolumn{2}{|c|}{ Model } & \multicolumn{2}{c|}{ UnstandardizedCoefficients } & StandardizedCoefficients \\
\cline { 3 - 5 } 1 & B & Std. Error & Beta \\
\cline { 2 - 5 } & (Constant) & 6.918 & 3.517 & \\
\cline { 2 - 5 } & FASILITAS & 0.507 & 0.178 & 0,043 \\
\cline { 2 - 5 } & $\begin{array}{l}\text { KUALITAS } \\
\text { PELAYANAN }\end{array}$ & 0.542 & 0.158 & 0,518 \\
\hline
\end{tabular}

Sumber : Data sekunder SPSS 20 Diolah, Tahun 2020

Dari tabel diatas dapat diketahui hasil analisis regresi diperoleh koefisien regresi yaitu variabel X1 sebesar 0,507, dan X2 sebesar 0,542 dengan konstanta sebesar 6,918 sehingga model persamaan regresi yang diperoleh adalah sebagai berikut:

$\mathrm{Y}=6,918+0,507 \mathrm{X} 1+0,542 \mathrm{X} 2+\mathrm{e}$

$\mathrm{Y}=$ Variabel dependen (kepuasan konsumen)

$\mathrm{X} 1=$ Variabel independen (fasilitas)

$\mathrm{X} 2$ = Variabel independen (kualitas pelayanan)

Berdasarkan persamaan regresi diatas mengenai variabel-variabel yang mempengaruhikepuasan konsumen, maka dapat dijelaskan sebagai berikut:

a. Konstanta sebesar 6.918 menyatakan bahwa jika variabel independen dianggap konstan, maka rata-rata kepuasan konsumen sebesar 6.918.

b. Koefisien regresi $\mathrm{X}_{1}$ (Fasilitas) dari perhitungan linier berganda dapat dilihat sebesar 0,507 hal ini berarti setiap ada peningkat fasilitas sebesar 1 konsumen maka kepuasan konsumen akan meningkat sebesar 0,507. Fasilitas dan kepuasan konsumen terjadi hubungan positif. Jika peningkatan fasilitas mengalami kenaikan maka Kepuasan Konsumen akan mengalami kenaikan atau bertambah.

c. Koefisien regresi berganda $\mathrm{X}_{2}$ (Kualitas Pelayanan) dari perhitungan regresi linier berganda dapat dilihat sebesar 0,542 hal ini berarti setiap ada peningkatan kualitas pelayanan sebesar 1 konsumen maka kepuasan konsumen akan meningkat sebesar 0,542. Maka kualitas pelayanan berpengaruh positif terhadap kepuasan konsumen.

Sehingga model regresi linier berganda dapat digunakan untuk memprediksi kepuasan konsumen yang dipengaruhi oleh fasilitas dan kualitas pelayanan.

\section{Uji Parsial (Uji T)}

Uji t digunakan untuk mengetahui pengaruh secara parsial variabel bebas terhadap variabel terikat. Pengujian ini yaitu dengan membandingkan nilai t tabel dengan menggunakan tingkat kesalahan $\alpha=0,05$. Kriteria yang digunakan adalah sebagai 
berikut :

- $\mathrm{H}_{0}$ diterima dan $\mathrm{H}_{1}$ ditolak jika nilai thitung $\leq \mathrm{t}$ tabel atau jika nilai sig $\geq 0,05$.

- $\mathrm{H}_{0}$ ditolak dan $\mathrm{H}_{1}$ diterima jika nilai thitung $\geq \mathrm{t}$ tabel atau jika nilai sig $\leq 0,05$. Tabel 2. Hasil Uji Parsial (Uji T) X1

\begin{tabular}{|c|c|c|c|c|c|c|}
\hline \multirow{2}{*}{ Model } & \multicolumn{2}{|c|}{$\begin{array}{c}\text { Unstandardized } \\
\text { Coefficients }\end{array}$} & $\begin{array}{c}\text { Standardized } \\
\text { Coefficients }\end{array}$ & \multirow{2}{*}{ t } & \multirow{2}{*}{ Sig. } \\
\cline { 2 - 7 } \multicolumn{2}{c|}{} & B & $\begin{array}{c}\text { Std. } \\
\text { Error }\end{array}$ & Beta & & \\
\hline \multirow{2}{*}{1} & (Constant) & -8.124 & 4.03 & & -2.016 & 0.052 \\
\cline { 2 - 7 } & FASILITAS & 1.053 & 0.092 & 0.894 & 11.444 & 0 \\
\hline
\end{tabular}

Sumber: Diolah dari hasil penelitian 2020

Hasil pengujian dengan SPSS diperoleh untuk variabel X1 (Fasilitas) diperoleh nilai t hitung $=11.444$ dengan tingkat signifikansi 0,000 . Dengan menggunakan batas signifikansi 0,05 , nilai signifikansi tersebut berada di atas taraf $5 \%(0,000<0,05)$ yang berarti Ho ditolak dan Ha diterima, dan t-tabel sebesar 1,68957, jadi diperoleh t-hitung $>$ t-tabel $(11.444>1,68957)$ Dengan demikian, maka Hipotesis diterima.

Tabel 3. Hasil Uji Parsial (Uji T) X2

\begin{tabular}{|c|c|c|c|c|c|c|}
\hline \multirow{2}{*}{ Model } & \multicolumn{2}{|c|}{$\begin{array}{c}\text { Unstandardized } \\
\text { Coefficients }\end{array}$} & $\begin{array}{c}\text { Standardized } \\
\text { Coefficients }\end{array}$ & \multirow{2}{*}{ t } & \multirow{2}{*}{ Sig. } \\
\cline { 2 - 5 } \multicolumn{2}{c|}{} & B & $\begin{array}{c}\text { Std. } \\
\text { Error }\end{array}$ & Beta & & \\
\hline \multirow{2}{*}{1} & (Constant) & -1.584 & 3.281 & & -0.483 & 0.632 \\
\cline { 2 - 6 } & $\begin{array}{c}\text { KUALITAS } \\
\text { PELAYANAN }\end{array}$ & 0.943 & 0.078 & 0.903 & 12.08 & 0 \\
\hline
\end{tabular}

Sumber: Diolah dari hasil penelitian 2020

Hasil pengujian dengan SPSS diperoleh untuk variabel X2 (Kualitas Pelayanan) diperoleh nilai $\mathrm{t}$ hitung $=12.08$ dengan tingkat signifikansi 0,000. Dengan menggunakanbatas signifikansi 0,05 , nilai signifikansi tersebut lebih kecil dari taraf $5 \%(0,000<0,05)$ yang berarti Ho ditolak dan Ha diterima, dan t-tabel sebesar 1,68957, jadi diperoleh t-hitung >t-tabel $(12.08>1,68957)$ Dengan demikian, maka Hipotesis diterima.

\section{Uji Simultan (Uji F)}

Uji F dilakukan untuk menguji pengaruh semua variabel independen secara serentakterhadap variabel dependen. Hasil uji $\mathrm{F}$ dapat dilihat berikut ini:

\begin{tabular}{|c|c|c|c|c|c|c|}
\hline \multicolumn{7}{|c|}{ Tabel 4. Hasil Uji Simultan (Uji F) } \\
\hline 1 & Megression & $\begin{array}{c}\text { Sum of } \\
\text { Squares }\end{array}$ & df & $\begin{array}{c}\text { Mean } \\
\text { Square }\end{array}$ & F & Sig. \\
\hline & Residual & 182.421 & 2 & 527.710 & 92.722 & $.000^{\mathrm{b}}$ \\
\hline & Total & 1237.543 & 32 & 5.691 & & \\
\hline
\end{tabular}

Sumber: Diolah dari hasil penelitian 2020

Dari tabel Anova uji F menghasilkan F-hitung sebesar 92.722 dengan nilai probabilitas (sig) 0,000, dan F-tabel sebesar 4,12 dengan nilai signifikansi 0.05. Karena nilai F-hitung > F-tabel $(92.722>4.12)$ maka menolak Ho dan menerima Ha. Jadi dapat disimpulkan bahwa ada pengaruh positif dan signifikan antara Fasilitas (X1) dan Kualitas Pelayanan (X2) secara bersama-sama terhadap Kepuasan Konsumen (Y).

\section{Uji Koefisien Determinasi}

Koefisien determinasi $\left(\mathrm{R}^{2}\right)$ mengukur seberapa jauh kemampuan model dalam menerangkan variasi variabel penjualan. Nilai koefisien determinasi antara 0 dan 1 . Nilai $\mathrm{R}^{2}$ yang mendekati satu berarti variabel independen penelitian memberikan 
hampir semua informasi yang dibutuhkan untuk memprediksi variasi variabel penjualan. Hasil koefisien determinasi dapat dilihat dalam tabel dibawah ini:

Tabel 5. Hasil Uji Koefisien Determinasi

\begin{tabular}{|c|c|c|c|c|}
\hline Model & R & R Square & $\begin{array}{c}\text { AdjustedR } \\
\text { Square }\end{array}$ & $\begin{array}{c}\text { Std. Errorof } \\
\text { the Estimate }\end{array}$ \\
\hline 1 & $.923 \mathrm{a}$ & 0.853 & 0.844 & 2.386 \\
\hline
\end{tabular}

Sumber: Diolah dari hasil penelitian 2020

Dari hasil tabel diatas dapat diketahui bahwa koefisien determinasi sebesar 0,923 dan Rsquare sebesar 0,853. Hal ini berarti 85,3\% kepuasan konsumen dapat dijelaskan oleh variabel Fasilitas dan kualitas pelayanan, sedangkan sisanya $(100-85,3)$ yaitu $14,7 \%$ kepuasan konsumen dipengaruhi oleh variabel-variabel lainnya yang tidak diteliti dalampenelitian ini.

\section{KESIMPULAN DAN SARAN}

\section{Kesimpulan}

Kesimpulan Berdasarkan hasilpenelitian dan pembahasan yang terdapat pada Bab IV maka dapat diperoleh beberapa kesimpulan. Kesimpulan ini sebagai jawabanatas rumusan masalah yang terdapat pada Bab I. Kesimpulan tersebut adalah sebagai berikut:

a. Variabel Fasilitas terbukti secara signifikan memiliki pengaruh positif sebesar 1,053 dengan probabilitas0,000 $<0,05$ pada tingkat signifikansi 5\% dengan $\mathrm{t}$ hitung $>\mathrm{t}$ tabel. Hal ini menunjukkan bahwa tingkat keandalanVega Hotel Kota Sorong dalam memberikan fasilitas yang tidak pernahmengecewakan dinilai positif oleh pengguna jasa.

b. Variabel Kualitas Pelayanan terbukti secara signifikan memiliki pengaruh positif sebesar 0,943 dengan probabilitas $0,000<0,05$ pada tingkat signifikansi $5 \%$ dengan $t$ hitung $>\mathrm{t}$ tabel terhadap kepuasan konsumen.Hal ini menunjukkan bahwa pengguna jasa memiliki penilaian yang positif terhadap kualitas pelayanan yang diberikan Vega Hotel Kota Sorong.

c. Penelitian ini juga menunjukan bahwa fasilitas dan kualitas pelayanan berpengaruh secara simultan terhadap kepuasan konsumen. Berdasarkan hasil analisis data diperoleh nilai f hitung > ftabel $(92.722>4.12)$ dan probabilitas dari korelasi tersebut sebesar 0,000 yang kurang dari 0,05. Hal inimenunjukkan pada tingkat signifikansi $5 \%$, fasilitas dan kualitas pelayanan berpengaruh secara simultan terhadap kepuasan konsumen.

\section{Saran}

Berdasarkan penelitian yang telah dilaksanakan, maka penulis mengemukakan beberapa saran sebagai berikut ini :

a. Vega Hotel Kota Sorong hendaknya berusaha senantiasa memperhatikan tingkat harga yang ditetapkan dan membandingkan dengan harga pesaing.Hal ini dilakukan agar harga yang ditetapkan Vega Hotel Kota Sorong merupakan harga yang bersaing mengingat Vega Hotel Kota Sorong bukan merupakan satu-satunya perusahaan penyedia jasa logistik yang berada di Indonesia. Dengan menetapkan harga yang bersaing tentu Vega Hotel Kota Sorong akan dapatterus bertahan sebagai perusahaan penyedia jasa logistik yang diminati masyarakat.

b. Bagi Vega Hotel KotaSorong hendaknya selalu tanggap dalam melayani kebutuhan konsumen serta lebih cepat dan tepat dalam memberikan bantuan yang dibutuhkan khususnya keluhan yang diberikan oleh konsumen agar mereka mendapatkan kepuasan atas pelayanan yangdiberikan. Perusahaan juga harus lebih meningkatkan fasilitas yang disediakandemi menunjang kenyamanan pengguna jasa saat melakukan 
transaksi. Hal ini juga dilakukan untuk lebih meningkatkan tingkat kepuasanpengguna saat menggunakan jasa VegaHotel Kota Sorong.

c. Bagi peneliti selanjutnya, diharapkan untuk lebih memperluas objek penelitian tidak hanya pada variabel harga dan kualitas pelayanan tetapi juga pada variabel-variabel lain sehingga diperoleh informasi yang lengkap tentang faktor-faktor yang mempengaruhi kepuasan konsumen dan penelitian berikutnya dapat lebih bermanfaat.

\section{DAFTAR PUSTAKA}

Ardani, W. (2019). Effect Of Product Innovation And Brand Awareness On Product Purchase Decisions Of PT. Unilever Indonesia. International Journal of Education, Information Technology, and Others, 2(1), 151-165.

A, U. (2003). Strategi Baru Manajemen Pemasaran, . Yogyakarta: Penerbit AMARA BOOKS,.

Asih, P. S., et al. 2021). Analisis Faktor-Faktor Yang Mempengaruhi Keputusan Pembelian Produk Fastfood KFC Di Kota Sorong (Studi Kasus Mega Mall Kota Sorong). Jurnal Ilmiah PERKUSI, 1(3), 352-356.

Basuki.Sulistyo. (2006). Metode Penelitian. Jakarta: Wedatama Widya Sastra. .

Christea.Frisdiantara. (2013). Pengaruh Dimensi Pelayanan Dan Dimensi Fasilitas Terhadap Kepuasan Mahasiswa Pada Universitas Kanjuruhan Malang,. Malang: Unversitas Kanjuruhan Malang.

Emzir. (2009). Metodologi PenelitianPendidikan. Jakarta: PT. Raja Grafindo Persada.

Erlangga, H., et al.(2021). Pengaruh Kualitas Pelayanan Dan Kualitas Produk Terhadap

Keputusan Pembelian Konsumen Sepeda Motor Honda Di PT Panca Sakti Perkasa

Di Bintaro. Jurnal Ilmiah PERKUSI, 1(4), 464-472.

Fandy.Tjiptono. (2000). Manajemen Jasa. Yogyakarta: Andi Offset.

Ghozali.Imam. (2009). Aplikasi Analisis Multivariate dengan Program SPSS “. Semarang: Undip.

Kasmad, K., et al. (2020). Influences of Price, Promotion, and Service quality on Communities' Interest in Choosing Vocational High School. Journal of Educational Science and Technology (EST), 6(2), 233-243.

Kotler.P. (2004). Manajemen Pemasaran. . Jakarta: PT. Indeks KelompokGramedia,.

L., W. W. (1994). Wilkie, William L. 1994. Consumer Behavior (third edition). New York. John . New York: John Willey \& Sons, Inc.

Nurjaya, N., et al. (2021). Pengaruh Brand Image Terhadap Keputusan Pembelian Pada PT. Wahana Motor Di Wilayah Cianjur. Jurnal Ilmiah PERKUSI, 1(2), 291-296.

Priyatno.Duwi. (2014). SPSS 22 Pengolah Data Terpraktis. Andi. Yogyakarta. Yogyakarta.: Andi.

Rasyid, N., et al. (2018). Pengaruh Bauran Pemasaran Terhadap Penjualan Pada PT. Nestle Indofood Citarasa Indonesia Di Makassar. SENTRALISASI, 7(2), 11-27.

Ratninnto. (2005). Manajemen pelayanan, Pengembangan model konseptual, Penerapan Chizen's Charter dan Standar Pelayanan Minimal. Jakarta: Pustaka Pelajar.

Rofianto, W., et al. (2021). Cultural Product Branding, Antecedents, And Its Implications:

A Study On The Context Of Indonesian Batik. International Journal Of Social, Policy And Law, 2(2), 37-46.

Sammeng, A. (2001). Cakrawala pariwisata. Jakarta: Balai Pustaka.

Sugiyono. (2009). Metode Penelitian Kuantitatif, Kualitatif dan R\&D. Bandung : Alfabeta.

Wangsi, M. M., et al. (2018). Perlindungan Konsumen Dalam Pelabelan Produk Menurut Ekonomi Islam. Sentralisasi, 7(1), 1-9. 